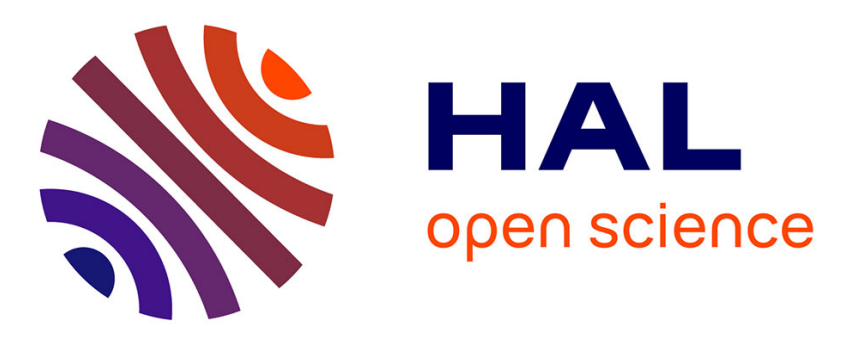

\title{
In vitro solubilization of fat-soluble vitamins in structurally defined mixed intestinal assemblies
}

Asma El Aoud, Emmanuelle Reboul, Aurélien Dupont, Cristelle Mériadec, Franck Artzner, Sébastien Marze

\section{- To cite this version:}

Asma El Aoud, Emmanuelle Reboul, Aurélien Dupont, Cristelle Mériadec, Franck Artzner, et al.. In vitro solubilization of fat-soluble vitamins in structurally defined mixed intestinal assemblies. Journal of Colloid and Interface Science, 2021, 589, pp.229-241. 10.1016/j.jcis.2021.01.002 . hal-03122063

\section{HAL Id: hal-03122063 \\ https://hal.inrae.fr/hal-03122063}

Submitted on 28 Jan 2021

HAL is a multi-disciplinary open access archive for the deposit and dissemination of scientific research documents, whether they are published or not. The documents may come from teaching and research institutions in France or abroad, or from public or private research centers.
L'archive ouverte pluridisciplinaire HAL, est destinée au dépôt et à la diffusion de documents scientifiques de niveau recherche, publiés ou non, émanant des établissements d'enseignement et de recherche français ou étrangers, des laboratoires publics ou privés. 

assemblies

3

4

5

6

7

Asma El Aoud,$^{1,2}$ Emmanuelle Reboul, ${ }^{2}$ Aurélien Dupont, ${ }^{3}$ Cristelle Mériadec, ${ }^{4}$ Franck Artzner, ${ }^{4}$ and Sébastien Marze ${ }^{1^{*}}$

1 INRAE, BIA, F-44316, Nantes, France

2 AMU, INRAE, INSERM, C2VN, Marseille, France

3 CNRS, Biosit, UMS 3480, Université de Rennes 1, US_S 018, F-35000, Rennes, France

4 CNRS, Institut de Physique de Rennes, UMR 6251, Université de Rennes 1, F-35000, Rennes, France

*Corresponding author: sebastien.marze@inrae.fr

\section{Abstract}

The structures of fed state intestinal assemblies containing bile components, dietary fat, and fatsoluble vitamins are not well known, although they are involved in lipid transport. In this study, several methods were used to investigate structural transitions upon various dietary lipids or various fatsoluble vitamins incorporation in bile intestinal assemblies. In particular, DLS and turbidimetry were used to study transition points as a function of component concentration, and cryo-TEM and SAXS were used to resolve assembly structures at microscopic and supramolecular scales, respectively. Results showed that increasing the concentration of dietary lipids in bile assembly induced a transition from core-shell micelles to unilamellar vesicles (except with caprylate lipids, always yielding micelles). In these specific assemblies, increasing the concentration of a fat-soluble vitamin either induced a systematic structural transition, defining a solubilization capacity ( $\alpha$-tocopherol or phylloquinone), or induced a structural transition only in micelles (retinol), or did not induce any structural transition up to very high concentrations (cholecalciferol). Using SAXS data, ideal molecular organizations are proposed for assemblies in the absence or presence of $\alpha$-tocopherol. 
Keywords: micelle, vesicle, lipid, bile, fat-soluble vitamin, solubilization, SAXS, cryo-TEM

\section{Introduction}

Upon the ingestion of food or medication, many physicochemical processes occur in the gastrointestinal tract to make nutrients or drugs bioaccessible (absorbable by the intestinal cells). These processes typically include mechanical breakdown, dissolution, enzymatic hydrolysis, molecular solubilization, and binding to specific carriers.

For lipids and lipophilic compounds, molecular solubilization in luminal water is actually insignificant, as their aqueous solubility is very low. Instead, transport to their absorption site takes place in supramolecular structures, usually called micelles, aggregates, or assemblies, composed of molecules secreted in the bile.

Thus, to be transported, lipids and lipophilic compounds have to be solubilized (i.e. incorporated) in bile assemblies. This critical step for absorption is commonly studied for poorly water-soluble drugs, but rarely for lipophilic nutrients. Solubilization ratio (defined as the molar or mass ratio of lipophilic compound to micellar bile salt) values are thus mainly available for drugs, although some data exist for fat-soluble vitamins (Wiedmann and Kamel, 2002).

In any case, assembly structure is an important aspect that was only reported in a few articles. It is indeed known from the seminal works of Small and/or Carey that physiological surfactants (such as bile salts and phospholipids) form various types of assembly, spherical micelles described for many synthetic surfactants only occurring in specific conditions (Carey and Small, 1970; Muller, 1981; Phan et al., 2015). For gallbladder bile, bilayer disk shapes (Small et al., 1969; Mazer et al., 1980; Muller, 1981; Madenci et al., 2011) and long cylinder shapes (Ulmius et al., 1982; Nichols and Ozarowski, 1990; Hjelm et al., 1992; Cohen et al., 1998) were mainly reported for bile salt-phospholipid systems, with a transition from small disks to large vesicles when cholesterol was added (Mazer and Carey, 1983). This transition was later found in the absence of cholesterol but upon dilution (Schurtenberger et al., 1985). 
Intermediate transitions were also found upon temporal rearrangement (Egelhaaf and Schurtenberger, 1999), from cylinders to disks to vesicles, the longest lived assemblies being disks and vesicles (Leng et al., 2003).

For intestinal bile, containing diluted bile and fat digestion products (fatty acid FA and monoglyceride $M G)$, disks and vesicles were found to coexist in the duodenal fluid of fed healthy humans (Hernell et al., 1990), which could be reproduced in vitro (Staggers et al., 1990). The coexistence of micelles and vesicles was again observed recently in the duodenal fluid of both fasted and fed healthy humans (Elvang et al., 2016; 2019), and reproduced in vitro, obtaining disk-like micelles and polydisperse vesicles (Elvang et al., 2016; 2018). However, an accurate characterization of standard simulated intestinal fluids using small-angle X-ray scattering (SAXS) contradicted this coexistence, multilamellar vesicles being only present in the fasted state, and core-shell ellipsoidal micelles being the only assembly in the fed state (Clulow et al., 2017). Moreover, ellipsoidal micelles were also identified in the fed state using small-angle neutron scattering (Rezhdo et al., 2017).

In the context of poorly water-soluble drug solubilization, the seminal works of Kossena et al. (2003; 2004) revealed transitions between mixed intestinal assemblies upon FA+MG addition. In their first article, they reported the coexistence of micelles and vesicles in both the fasted state (low bile concentration) and the fed state (high bile concentration), drug solubilization being higher in the presence of digestion products, and in the fed state (Kossena et al., 2003). In their second article, in the fasted state, they confirmed the coexistence of micelles and vesicles, the latter being unilamellar or multilamellar at low or high FA+MG concentration, respectively. At even higher FA+MG concentration, lamellar liquid crystal or cubic liquid crystal were found depending on the type of FA and MG (C8:0, caprylate; $\mathrm{C} 12: 0$, laurate; $\mathrm{C} 18: 1$; oleate). Drug solubilization was higher at higher FA+MG concentration, and in liquid crystal phases (Kossena et al., 2004). Later, the same research group reported a transition from pure micelles to coexisting micelles and vesicles with increasing FA+MG concentration in the fasted state, leading to drug solubilization increase (Birru et al., 2017). Finally, Ilardia-Arana et al. (2006) and Kleberg et al. (2010) also reported a transition from pure micelles to 
coexisting micelles and vesicles with increasing FA+MG concentration in both fasted and fed states, leading to drug solubilization increase.

Although these works clearly identified the transitions and the various assemblies obtained in the presence of $F A+M G$, their structures upon drug solubilization were only characterized once (Nielsen et al., 2001). Moreover, only drug solubilization was investigated using this approach, and no systematic study was reported for the solubilization of fat-soluble vitamins.

To fill these gaps, we conducted a systematic solubilization study of fat-soluble vitamins using a relevant composition of intestinal bile (including lysophosholipids) in the fed state. First, the effect of increasing FA+MG concentration in intestinal bile assemblies was determined as a function of FA and MG type (C8:0, C18:1, C22:6, docosahexaenoate). Both the concentration and the type of FA and MG were indeed anticipated to influence assembly structures and transitions. Several techniques (turbidimetry, cryo-TEM, DLS, SAXS) were used to cover macroscopic to molecular scales, enabling the characterization of two distinct assemblies. Then, the solubilization capacity, expected to depend on the structure and composition of these assemblies, was determined by addition of increasing amounts of fat-soluble vitamins, checking assembly structures and transitions using the same techniques.

\section{Materials}

Sodium taurocholate (86339), the lysophosphatidylcholines (855675P, 845875P), cholesterol (C3045), cholecalciferol (C9756), retinol (95144), phylloquinone (95271), and $\alpha$-tocopherol (T3251) were purchased from Sigma-Aldrich, France. Phosphate-buffered saline (PBS; $155 \mathrm{mM} \mathrm{NaCl}, 2.7 \mathrm{mM}$ $\left.\mathrm{Na}_{2} \mathrm{HPO}_{4}-7 \mathrm{H}_{2} \mathrm{O}, 1.5 \mathrm{mM} \mathrm{KH} \mathrm{PO}_{4}\right) \mathrm{pH} 7.2$ (20012019) was purchased from Thermo Fisher Scientific, France. Caprylic acid (N-8-A), palmitic acid (N-16-A), oleic acid (U-46-A), docosahexaenoic acid (U-84A), monocaprylin (M-114), monoolein (M-239), and monodocosahexaenoin (M-314) were purchased from Nu-Chek Prep, USA.

\section{Methods}




\subsection{Intestinal bile compositions}

Simple intestinal bile (SIB) composition was designed to mimic that in the duodenal lumen of the mouse. Bile salt concentration was found to be around $20 \mathrm{mM}$ in mouse upper intestine (Tannock et al., 1994). Based on mouse biliary output ratios between bile salt, phospholipid and cholesterol (Werner et al., 2002; Kok et al., 2003), we deduced phospholipid and cholesterol concentrations in mouse upper intestine of $3 \mathrm{mM}$ and $0.25 \mathrm{mM}$, respectively. To simplify the system, we used the most abundant bile salt in the mouse, taurocholate (Baghdasaryan et al., 2016; Pathak et al., 2018), and also the most abundant phospholipids, phosphatidylcholines containing 16:0 or 18:1 fatty acids (Agellon et al., 1999). Each phospholipid was included in the system as one lysophosphatidylcholine plus one free fatty acid. The resulting composition is reported in table 1.

\begin{tabular}{|c|c|c|c|c|c|c|}
\hline Concentration & TC & $16: 0$ LPC & $18: 1 \mathrm{LPC}$ & PA & OA & CH \\
\hline $\mathrm{mM}$ & 19 & 1.55 & 1.45 & 1.55 & 1.45 & 0.25 \\
\hline $\mathrm{mg} \mathrm{mL}^{-1}$ & 10 & 0.75 & 0.75 & 0.40 & 0.40 & 0.10 \\
\hline
\end{tabular}

Table 1: Composition of the simple intestinal bile SIB (TC: taurocholate, LPC: Iysophosphatidylcholine, PA: palmitic acid, OA: oleic acid, $\mathrm{CH}$ : cholesterol).

The range of FA+MG addition to the SIB to make the mixed intestinal assemblies was determined by estimating a mass ratio of fat intake to bile salt output in vivo in the rat (no data available for the mouse). This ratio was typically comprised between 3.0 and 7.0 for ad libitum diets (Boquillon and Clement, 1979; Sugano et al., 1983). However, for restricted diets, this ratio could be as low as 0.5 , as found in the human (Grundy and Metzger, 1972) and in the pig (Juste et al., 1983). We thus selected a range between 0.5 and 4.0 for the FA+MG/TC mass ratio, keeping a FA:MG molar ratio of 2:1, as obtained upon triglyceride hydrolysis by gastrointestinal lipases. The resulting FA and MG concentrations used are reported in table 2. 


\begin{tabular}{|c|c|c|c|c|c|c|}
\hline Concentration & $\mathrm{CA}$ & $\mathrm{MC}$ & $\mathrm{OA}$ & $\mathrm{MO}$ & $\mathrm{DHA}$ & $\mathrm{MDH}$ \\
& & & & & & \\
\hline $\mathrm{mM}$ & $19.8-$ & $9.9-$ & $10.8-$ & $5.5-$ & $9.6-$ & $4.6-$ \\
& 158 & 79 & 86 & 44 & 77 & 37 \\
\hline $\mathrm{mg} \mathrm{mL}^{-1}$ & $2.85-$ & $2.15-$ & $3.05-$ & $1.95-$ & $3.15-$ & $1.85-$ \\
& 22.8 & 17.2 & 24.4 & 15.6 & 25.2 & 14.8 \\
\hline
\end{tabular}

129

130

131

132

133

Table 2: Concentration ranges of FA and MG added to the simple intestinal bile SIB to make mixed intestinal assemblies (CA: caprylic acid, MC: monocaprylin, OA: oleic acid, MO: monoolein, DHA: docosahexaenoic acid, $\mathrm{MDH}$ : monodocosahexaenoin). The total mass concentration range of FA+MG is invariable, between 5.0 and 40.0 $\mathrm{mg} \mathrm{mL} \mathrm{L}^{-1}$. Note that molar concentrations depend on FA and MG type, resulting in FA+MG/TC molar ratios between 0.75 and 12.5 , especially different for the CA+MC systems.

Finally, the ranges of vitamin addition to the mixed intestinal assemblies, reported in table 3 , were estimated from literature values of i) rodent vitamin intake (Reeves et al., 1993), as the absorption of vitamins from these assemblies will be later tested in the mouse, ii) human upper vitamin intake to select the maximal values, and iii) mass solubilization ratios (SR, defined here as the ratio of the lipophilic compound mass to the taurocholate mass), which will be discussed later. 


\begin{tabular}{|c|c|c|c|c|}
\hline $\mathrm{C}\left(\mathrm{mg} \mathrm{mL}^{-1}\right)$ & $0.3 .10^{-3}-3$ & $5.10^{-3}-5$ & $0.1-10$ & $0.5-31.5$ \\
\hline $\mathrm{SR}\left(\mathrm{mg} \mathrm{mg}^{-1} \mathrm{TC}\right)$ & $0.03 .10^{-3}-0.3$ & $0.5 .10^{-3}-0.5$ & $0.01-1$ & $0.05-3.15$ \\
\hline
\end{tabular}

147

Table 3: Molar mass (M), concentration (C), and SR ranges of vitamins added to the mixed intestinal assemblies.

\subsection{Sample preparation}

Stock solutions in chloroform/methanol (2:1 v:v) were prepared by weighing i) the components of simple intestinal bile (except taurocholate), ii) the fatty acid and monoglyceride, and iii) the vitamin. These stock solutions were prepared in a dark room, stored in the dark at room temperature, and used within 5 days. To prepare the samples (usually 11 samples simultaneously), appropriate volumes of each solution were transferred to small volume amber vials to bring the correct mass for each component, with a maximal total volume of $2 \mathrm{~mL}$. The chloroform/methanol solvent was then totally evaporated under nitrogen until a lipid film was obtained. Finally, $2 \mathrm{~mL}$ of $10 \mathrm{mg} \mathrm{mL}^{-1}$ taurocholate solution in PBS was added, yielding samples with concentrations indicated in tables 1-2-3. These samples were kept at rest for 1 hour to ensure total hydration of the lipid film.

The samples were transferred to round bottom $1 \mathrm{~cm}$ plastic tubes for individual sonication using a Misonix Sonicator 4000 equipped with a microtip probe 419 (Qsonica, Connecticut, USA). During the sonication, the sample was kept on ice to prevent temperature increase. Each sample was sonicated for $5 \mathrm{~min}$ at $15 \mathrm{~W}$, bringing a total energy of $4.5 \mathrm{~kJ}$, with 1 min pause each 1 min sonication, again to prevent temperature increase. Then, the $\mathrm{pH}$ of each sample, measured with a microelectrode $(\mathrm{HI} 1083$, Hanna Instruments, France), was brought to $7.0 \pm 0.1$ using 10 to $30 \mu \mathrm{L}$ of $2 \mathrm{M} \mathrm{NaOH}$. Finally, each sample was filtered using a $0.22 \mu \mathrm{m}$ porosity RC membrane (Minisart $17821 \mathrm{~K}$, Sartorius). Whenever vitamin was present in the sample, a preliminary filtration using a $0.45 \mu \mathrm{m}$ porosity $\mathrm{RC}$ membrane (Phenex AF0-2103-12, Phenomenex) was performed to prevent plugging of the $0.22 \mu \mathrm{m}$ filter. All samples were stored in the dark at room temperature, and characterized within 48 hours after 
preparation (24 hours in the presence of vitamin). Each sample was prepared at least twice, on

171

172

173

174

175

176

177

178

179

180

181

182

183

184

185

186

187

188

189

190

191

192

193

194

195

different days.

\subsection{Sample characterization}

Results are expressed as average \pm standard deviation, except where noted. In most figures, independent samples are shown, the error bar of several measurements on a specific sample being within the symbol size.

\subsubsection{Dynamic light scattering}

Back-scattering size distribution measurement was performed at $20{ }^{\circ} \mathrm{C}$ using a Zetasizer Nano ZS dynamic light scattering (DLS) apparatus (Malvern Instruments Ltd, Worcestershire, UK) equipped with a $4 \mathrm{~mW}$ He-Ne laser at $\lambda=633 \mathrm{~nm}$. The exact angle between the laser beam and the detector (avalanche photodiode) is 173 . The refractive index value for the PBS was set to 1.33 . For the lipids, the refractive index of the most abundant lipid was used for each system, that is $1.43,1.46,1.52$, or 1.56 for $\mathrm{CA}, \mathrm{OA}, \mathrm{DHA}$, or $\mathrm{TC}$, respectively. It was checked that the results were the same when the refractive index of the lipid mixtures was estimated according to the real composition of each system. The absorption was always set to 0.001 . Undiluted samples of $1 \mathrm{~mL}$ were placed in disposable $12 \mathrm{~mm}$ square polystyrene cuvettes with $1 \mathrm{~mm}$ thick walls (Brand, Wertheim, Germany). A $30 \mathrm{~s}$ acquisition time was used to obtain a stable autocorrelation function. For each sample, the result is given as the average of the number-based mean diameter over 10 to 20 measurement repetitions.

\subsubsection{Turbidimetry}

The turbidity of $1 \mathrm{~mL}$ undiluted samples was measured at $20^{\circ} \mathrm{C}$ in the same disposable cuvettes, characterized as the absorbance at $\lambda=600 \mathrm{~nm}$ using a transmission UV-vis spectrophotometer (UV1800, Shimadzu, France).

\subsubsection{Small-angle $X$-ray scattering}

A home-made laboratory SAXS setup was used (Bizien et al., 2015) to analyze the structural organization of the samples. Scattering results were collected with a Pilatus $300 \mathrm{~K}$ (Dectris, Switzerland), mounted on a microsource X-ray generator GeniX 3D (Xenocs, France) operating at $30 \mathrm{~W}$. 
The monochromatic CuK $\alpha$ radiation of $\lambda=1.541 \AA$ is selected by an asymmetric multilayer mirror (Xenocs, France), and the beam is defined by two sets of slits. The results were recorded in a reciprocal space $q=(4 \pi \cdot \sin \theta) / \lambda$ in a range of repetitive distances from 0.013 to $1.72 \AA^{-1}$. The channel to scattering vector (q) calibration of the detector was carried out with silver behenate.

Samples of $10 \mu \mathrm{L}$ were placed in thin quartz capillaries of $1.5 \mathrm{~mm}$ diameter (GLAS W. Muller, Berlin, Germany) for the measurements. Up to 19 samples were measured successively at $20^{\circ} \mathrm{C}$, with 1 hour of acquisition for each sample. The pure solvent (PBS at pH 7.0) was always one of the samples, enabling the subtraction of the solvent background intensity in the analysis of the other samples, proportionally to the amount of solvent they contain.

The intensity profiles were modelled using SasView v4.1.2. Based on the literature results, the coreshell cylinder (able to fit both flat disk and long cylinder), the core-shell ellipsoid (able to fit both oblate and prolate ellipsoid), and the core-multi-shell sphere (a core-shell sphere with a given number of shells) models were tested (see SasView website). Their parameters were the same, being the background intensity, the intensity scale, the scattering length densities (SLD of the core, shell, and solvent), and specific geometric dimensions (length, radius, thickness). To reduce the number of free parameters, the Guinier model was applied in the low-q region of the intensity profile where q.Rg $\leq$ $1.3, \mathrm{Rg}$ being the radius of gyration of the object. This enabled the determination of $\mathrm{Rg}$ and of the intensity scale, the latter being then fixed in the other models. The scattering length density of each molecule was calculated using the SLD calculator of SasView, based on its molecular formula and its mass density. As the assemblies are made of complex mixtures, the exact SLD of core and shells are not known, so the calculated range was used to set initial guesses, letting the values free for the fit, except that of pure water (the solvent), fixed to the calculated value of $9.45 .10^{-6} \AA^{-2}$ at $20^{\circ} \mathrm{C}$. The SLD initial guess for the core was either set to that of pure water or to an average value of the lipid tails, depending on the model used. The SLD initial guess for the shell was set to an average value for lipid headgroups and surface molecules (bile salt and cholesterol). The radius of gyration was also used for 
the initial guesses of the geometric dimensions, testing initial aspects ratio of $0.5,1$, and 2 in the cylinder and the ellipsoid models.

\subsubsection{Cryo-TEM}

Vitrification of samples was performed using an automatic plunge freezer (EM GP, Leica) under controlled humidity and temperature (Dubochet and McDowall, 1981). The samples were deposited on glow-discharged electron microscope grids, followed by blotting and vitrification by rapid freezing into liquid ethane. Grids were transferred to a single-axis cryo-holder (model 626, Gatan) and were observed using a $200 \mathrm{kV}$ electron microscope (Tecnai G2 T20 Sphera, FEI) equipped with a 4k $\times 4 \mathrm{k}$ CCD camera (model USC 4000, Gatan). Micrographs were acquired under low electron doses using the camera in binning mode 1 and at a nominal magnification of $29000 x$.

\section{Results}

\subsection{Mixed intestinal assemblies}

\subsubsection{Dynamic light scattering}

Increasing concentration of FA+MG in simple intestinal bile had different effects on the number-based mean diameter ( $\mathrm{Dn}$ ) of the mixed intestinal assemblies depending on the type of lipid added (figure 1). $\mathrm{CA}+\mathrm{MC}$ concentration had almost no effect on $\mathrm{Dn}$, with an average value of $3.3 \pm 0.1 \mathrm{~nm}$ for the first sample series (exp1), and of $3.3 \pm 0.2 \mathrm{~nm}$ for the second sample series (exp2). This was similar to the average value for the SIB samples, of $3.7 \pm 0.3 \mathrm{~nm}$. For $\mathrm{OA}+\mathrm{MO}$ and $\mathrm{DHA}+\mathrm{MDH}$, increasing $\mathrm{FA}+\mathrm{MG}$ concentration resulted in increased assembly diameter, with reproducible values extracted from number-based unimodal distributions up to $8.5 \mathrm{mg} \mathrm{mL}^{-1}$. This point was defined as the transition concentration, above which a steep size increase occurred. This was followed by a transition region between 12 and $26 \mathrm{mg} \mathrm{mL}^{-1}$, with increasing $\mathrm{Dn}$ values that were poorly reproducible between independent samples, due to the coexistence of two assembly types (intensity-based distributions became more bimodal, resulting in more polydisperse number-based distributions). Between 29.5 and $40 \mathrm{mg} \mathrm{mL}^{-1}$, distributions became less polydisperse again, so Dn values were more reproducible, with 

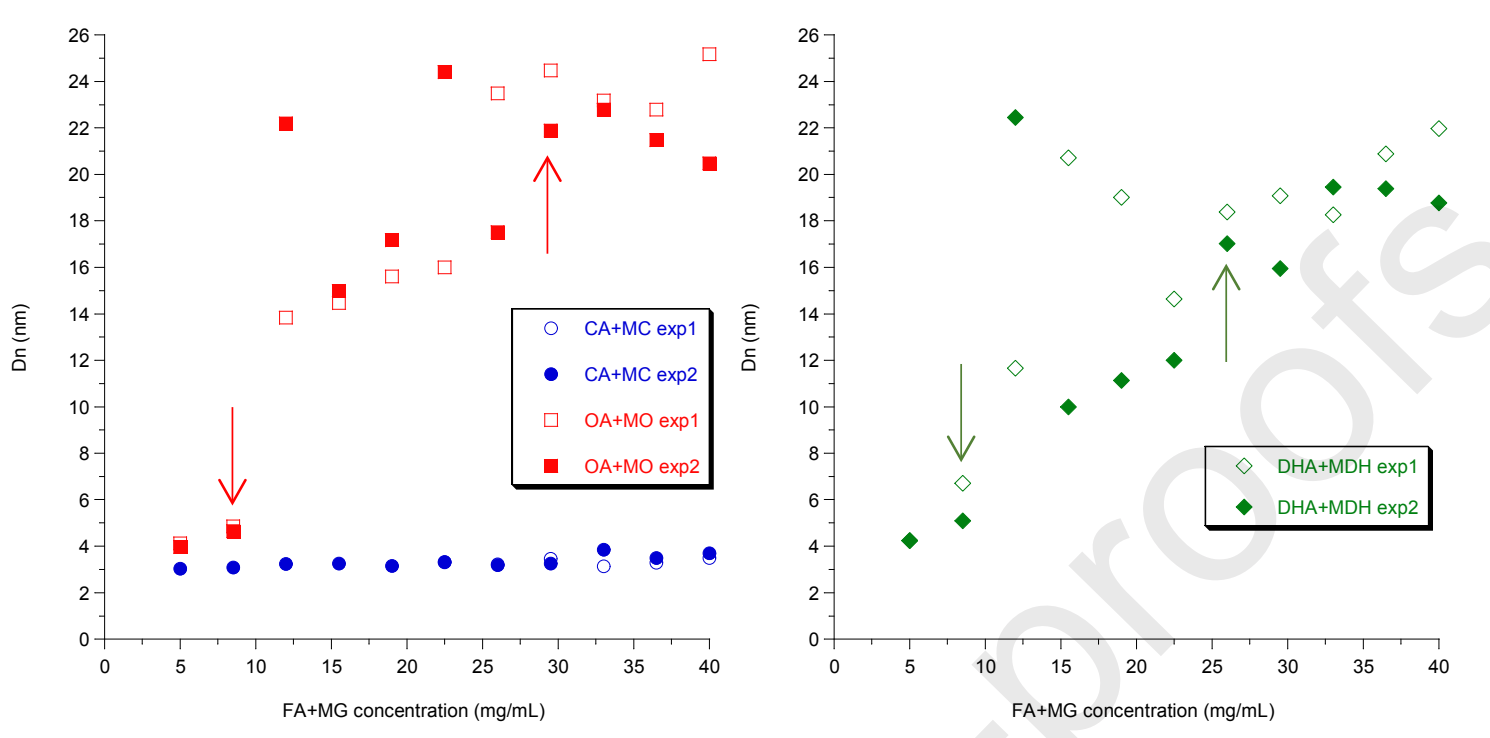

Figure 1: Number-based mean diameter (Dn) of the mixed intestinal assemblies determined by DLS, as a function of FA+MG concentration for each system. Exp1 and exp2 refers to independent sample series preparation and characterization. The arrows indicate the beginning and the end of the transition region.

\subsubsection{Turbidimetry}

In agreement with the DLS results, sample absorbance (turbidity) did not change significantly with increasing $C A+M C$ concentration, but greatly increased with increasing $\mathrm{OA}+\mathrm{MO}$ or $\mathrm{DHA}+\mathrm{MDH}$ concentration (figure 2). For these systems, turbidity increased slightly up to a transition concentration after which it raised abruptly, finishing with a steep increase up to $40 \mathrm{mg} \mathrm{mL}^{-1}$. The transition concentration was either 26 or $22.5 \mathrm{mg} \mathrm{mL}^{-1}$ for $\mathrm{OA}+\mathrm{MO}$, and was always found to be $26 \mathrm{mg} \mathrm{mL}^{-1}$ for $\mathrm{DHA}+\mathrm{MDH}$. These values corresponded to the end of the transition region defined with DLS results. 

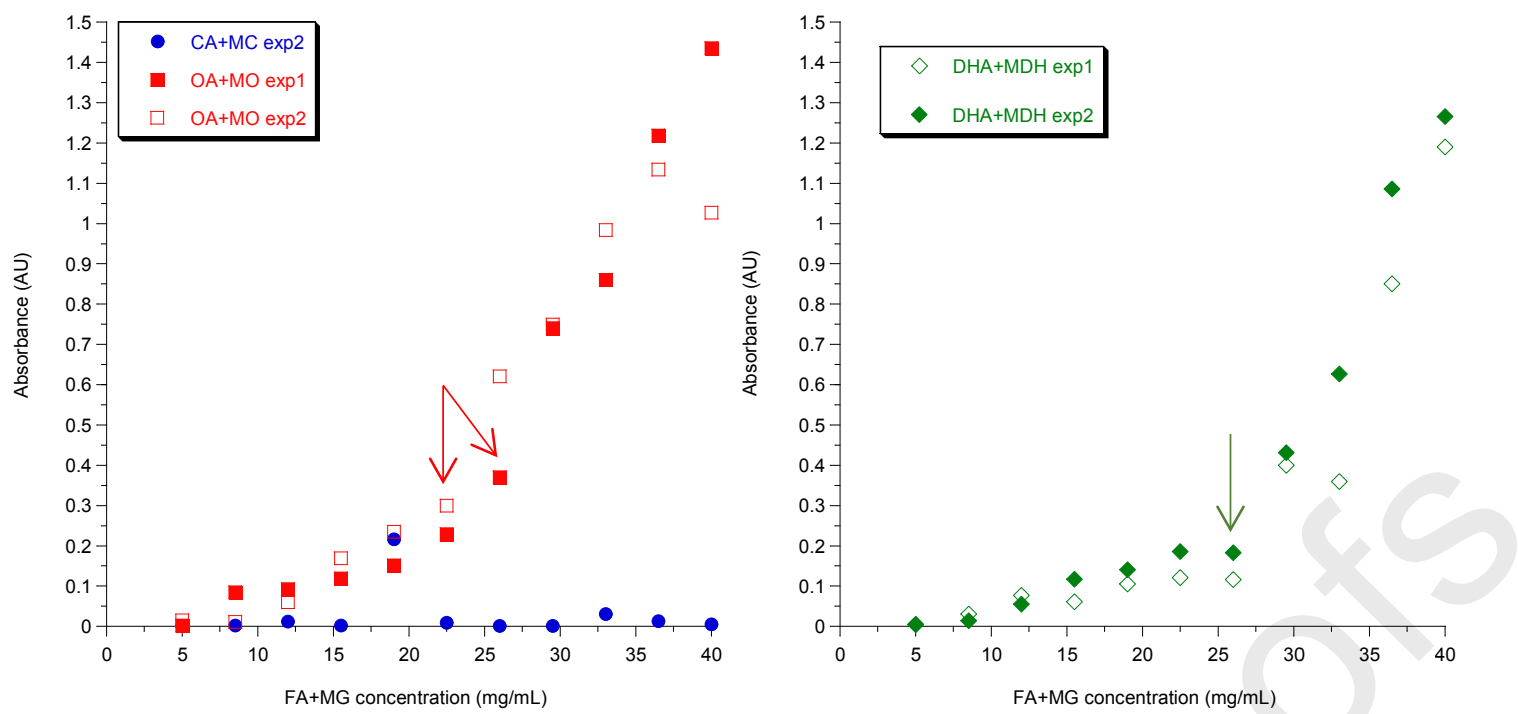

Figure 2: Absorbance of the mixed intestinal assemblies determined by turbidimetry, as a function of FA+MG concentration for each system. Exp1 and exp2 refers to independent sample series preparation and characterization. The arrows indicate the transition concentrations.

\subsubsection{Small angle $X$-ray scattering}

As DLS results are based on sphere size distribution, giving no indication on the structure and shape of the measured objects, SAXS measurements were performed to characterize these features in the whole $F A+M G$ concentration range. Figure 3 shows representative examples of the intensity profile for the different mixed intestinal assemblies at various $F A+M G$ concentrations, at $20{ }^{\circ} \mathrm{C}$. The effect of temperature was tested for several systems, and no change was observed in the intensity profile in the range $20-60^{\circ} \mathrm{C}$. Overall, each system displayed specific intensity profiles. Those for CA+MC mixed 275 intestinal assemblies were similar within the concentration range, with a broad peak at high q values and a plateau at low q values (with further intensity increase at lower q values in some cases). This broad peak indicated a core-shell structure and the plateau enabled the determination of a small finite size. Such profiles were also observed for $\mathrm{OA}+\mathrm{MO}$ and $\mathrm{DHA}+\mathrm{MDH}$ mixed intestinal assemblies up to 8 $\mathrm{mg} \mathrm{mL}^{-1}$, changing significantly in the transition region defined with DLS results, reaching a final specific profile at 22.5 and $29.5 \mathrm{mg} \mathrm{mL}^{-1}$ for $\mathrm{OA}+\mathrm{MO}$ and $\mathrm{DHA}+\mathrm{MDH}$, respectively. These profiles were 
and an upward slope in the lowest q region. Again, a core-shell structure can be presumed, likely

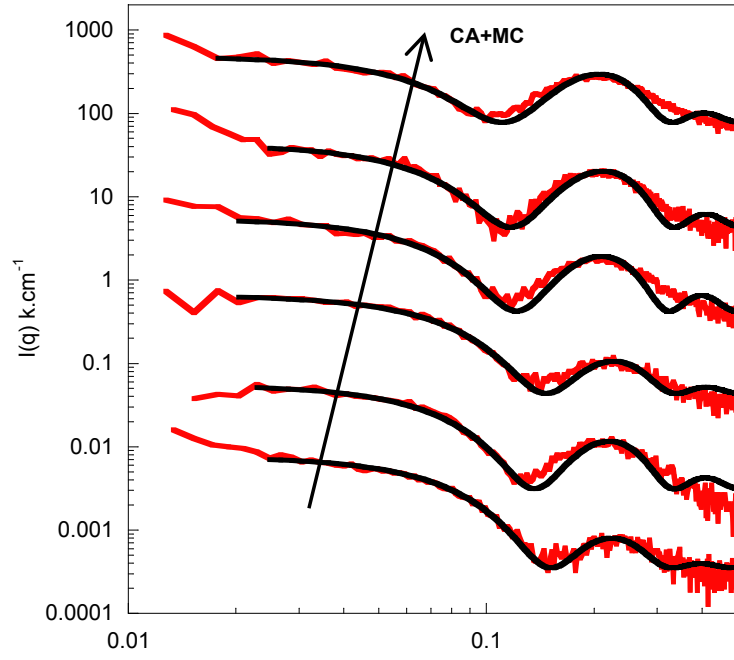

$q\left(\AA^{-1}\right)$
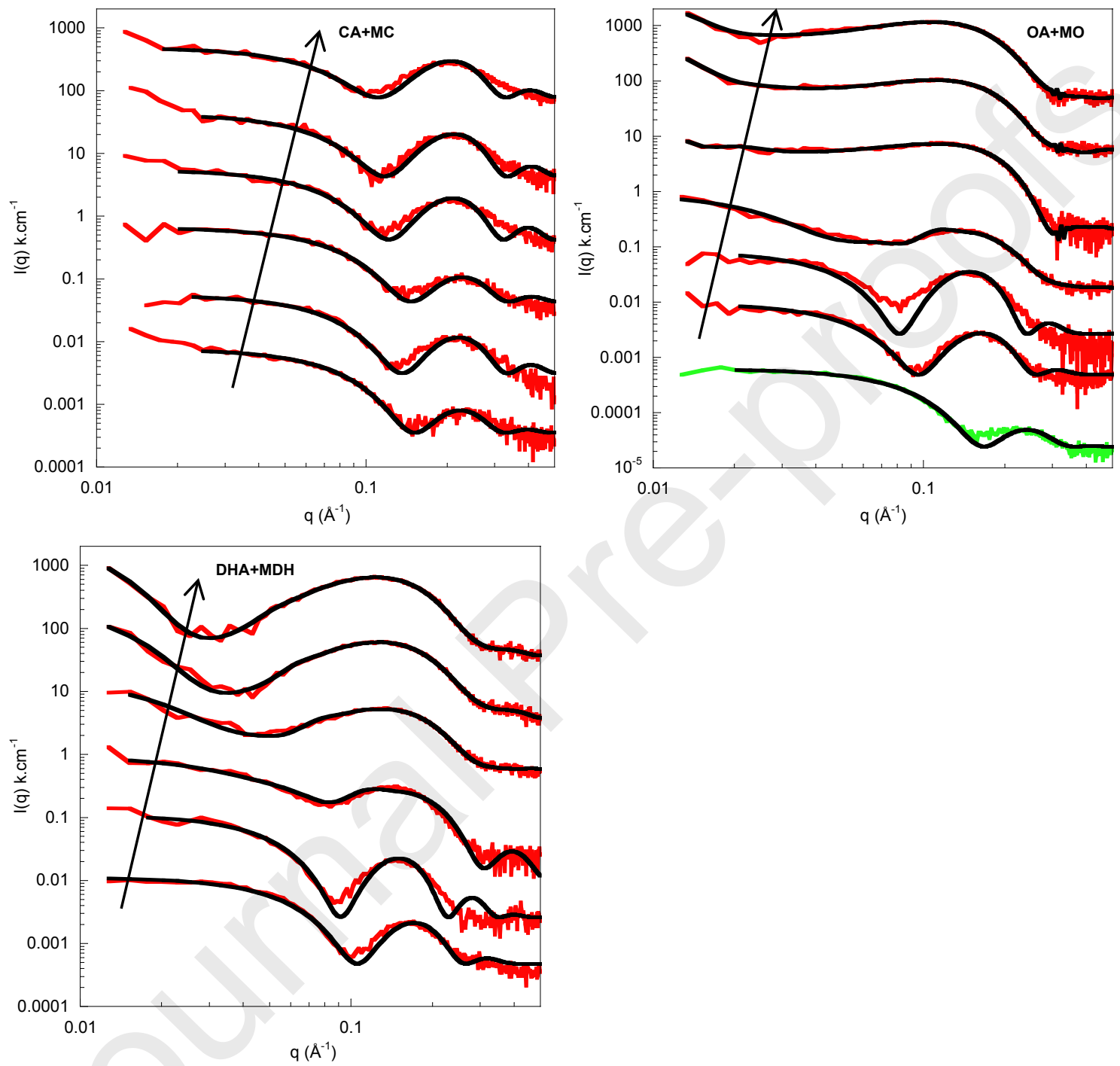

Figure 3: Representative SAXS intensity profiles for mixed intestinal assemblies at $20{ }^{\circ} \mathrm{C}$ with increasing concentrations $\left(5,8.5,15.5,26,33,40 \mathrm{mg} \mathrm{mL}^{-1}\right)$ of $\mathrm{CA}+\mathrm{MC}$ (top left), OA+MO (top right), or DHA+MDH (bottom).

The intensities of successive profiles are shifted by a 10-fold factor, those for the lowest concentration not being with the core-multi-shell sphere model. 
To go further and extract morphological features, intensity profiles for the full concentration series were fitted using the three models described in 3.3.3. The core-shell cylinder model did not capture any profile correctly, resulting in low goodness of fit values. The core-shell ellipsoid model was able to fit the profiles with high goodness of fit values, but returned consistent aspect ratio and SLD values only for $\mathrm{CA}+\mathrm{MC}$ and for the first two $\mathrm{OA}+\mathrm{MO}$ or $\mathrm{DHA}+\mathrm{MDH}$ concentrations, i.e. up to the transition concentration defined with DLS results. The best model over the whole FA+MG concentration range was the core-multi-shell sphere, resulting in equivalently high goodness of fit values and returning consistent SLD values. The fits for the core-multi-shell sphere model are shown in figure 3. Specifically, a monodisperse water-core two-shell model (reducing to a lipid core one-shell model as the water core radius was fitted to a zero value) was found to be optimal for $C A+M C$ and at low $O A+M O$ and DHA+MDH concentrations, whereas a polydisperse water-core three-shell model was found to be optimal starting from the middle of the transition region for $\mathrm{OA}+\mathrm{MO}$ and $\mathrm{DHA}+\mathrm{MDH}$ (optimal core size polydispersity of 0.5 and 0.25 , respectively).

To facilitate parameter comparison, the core-multi-shell sphere model was preferred for all systems although it did not perfectly fit some systems at intermediate to high q values (figure 3). Indeed, better fits were obtained at intermediate to high q values with the oblate core-shell ellipsoid model (average aspect ratio of $0.55 \pm 0.15$ ) for $\mathrm{CA}+\mathrm{MC}$ and for the first two $\mathrm{OA}+\mathrm{MO}$ or $\mathrm{DHA}+\mathrm{MDH}$ concentrations, indicating deformed spheroids rather than perfect spheres. However, this model was unstable above these first two $\mathrm{OA}+\mathrm{MO}$ or $\mathrm{DHA}+\mathrm{MDH}$ concentrations, returning highly variable aspect ratio and SLD values, making it unsuitable for our purpose of studying assembly transition regions. To illustrate these core-shell ellipsoid results, fits for the lowest and highest FA+MG concentrations in all systems are shown in figures $\mathrm{S} 2$ and $\mathrm{S} 3$.

The parameters of the core-multi-shell sphere model are given in table S1 and some geometric dimensions are plotted in figure 4 (parameters of the core-shell ellipsoid model are also given in figures S2 and S3). As seen in table S1, the parameter values were close for duplicate or triplicate samples, indicating reproducible sample preparation. From these data, two types of assembly could be 
identified: i) lipid-core-shell micelles for $\mathrm{CA}+\mathrm{MC}$ and at low $\mathrm{OA}+\mathrm{MO}$ and $\mathrm{DHA}+\mathrm{MDH}$ concentrations

321 (fitted water core radius of 0 in table S1), ii) water-core vesicle with a three-shell membrane for

$322 \mathrm{OA}+\mathrm{MO}$ and $\mathrm{DHA}+\mathrm{MDH}$ at intermediate to high concentrations (figure 4 illustrations). The main transition evidenced in figure 4 for $\mathrm{OA}+\mathrm{MO}$ and $\mathrm{DHA}+\mathrm{MDH}$ occured at intermediate concentrations compared to those determined by DLS and turbidimetry. However, in detail, a transition region similar to the one defined with DLS results was identified, in which the external or the internal shell thickness was abnormally thin (table S1). This was an artifact probably due to micelle-vesicle coexistence. The values of the assembly total diameter (D) deduced from the SAXS measurements (figure 4) were systematically $40 \pm 3 \%$ larger than those determined by DLS (Dn). These calculated diameters were thus consistently related, although their absolute values differed from one technique to the other. 

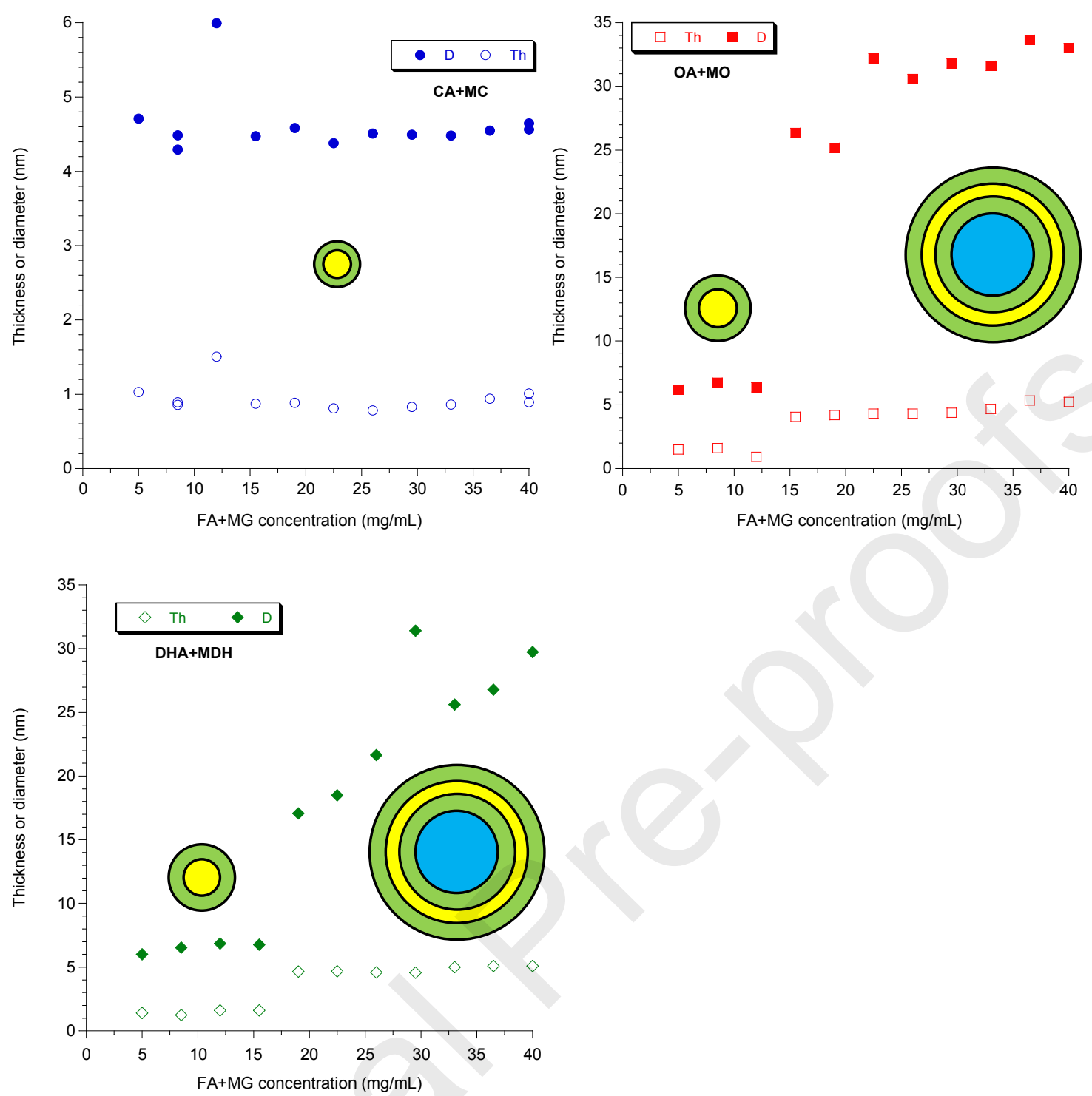

Figure 4: Main parameters of the core-multi-shell sphere model (total diameter $D$, and shell thickness Th) for mixed intestinal assemblies containing $C A+M C$ (top left), OA+MO (top right), and DHA+MDH (bottom). Illustrations are drawn to scale, except vesicles for which only the membrane is drawn to scale. 

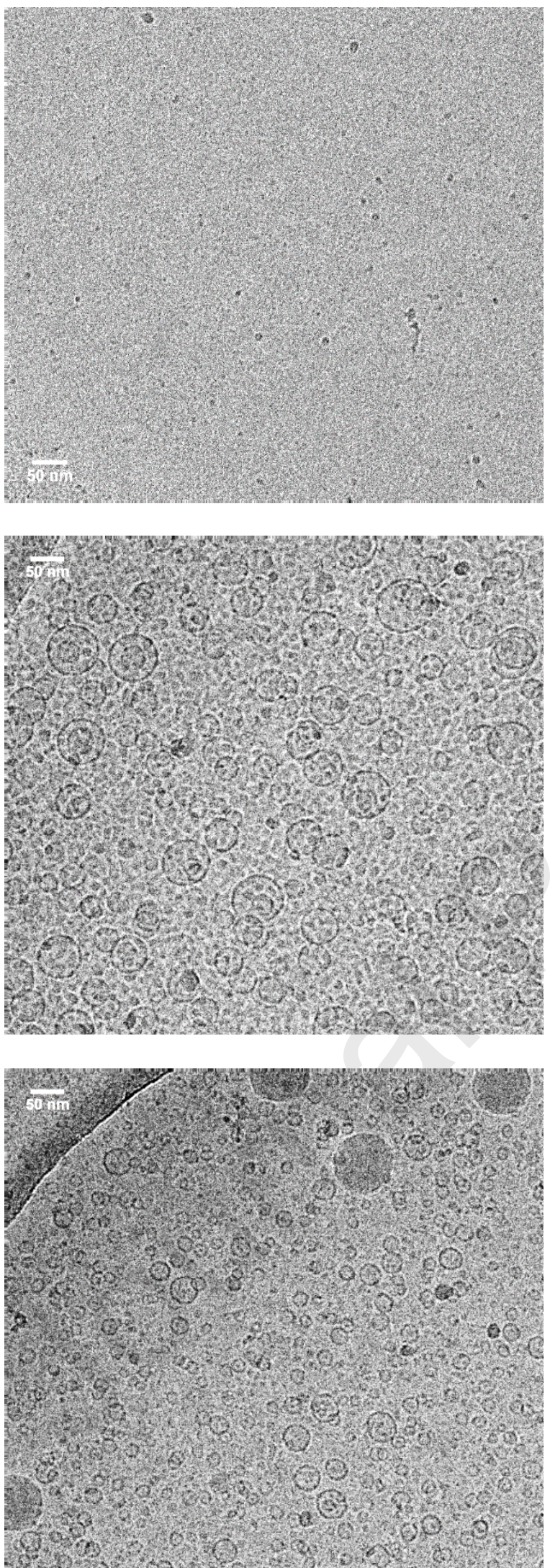
at $40 \mathrm{mg} \mathrm{mL}^{-1}$, middle), and $\mathrm{DHA}+\mathrm{MDH} 40$ (DHA+MDH at $40 \mathrm{mg} \mathrm{mL}^{-1}$, bottom) systems. 
Systems including the lowest and highest FA+MG concentration (denoted FA+MG 5 and FA+MG 40, respectively) were observed under cryo-TEM to check the assemblies and their size. These observations confirmed that $\mathrm{OA}+\mathrm{MO} 40$ and $\mathrm{DHA}+\mathrm{MDH} 40$ systems contained unilamellar vesicles, ranging from 20 to $60 \mathrm{~nm}$ and from 10 to $40 \mathrm{~nm}$, respectively. This also confirmed that vesicles containing $\mathrm{OA}+\mathrm{MO} 40$ were larger and more polydisperse than vesicles containing $\mathrm{DHA}+\mathrm{MDH} 40$. This was also in agreement with the mean diameters determined by DLS and SAXS, comprised in these ranges. In the OA+MO 40 system, some vesicles above $60 \mathrm{~nm}$ contained a smaller vesicle in their $\mathrm{nm}$ were observed, in agreement with the DLS and SAXS results. Most of them seemed spherical and a few resembled slightly deformed spheroids, but cryo-TEM resolution was not high enough to investigate their exact morphology.

\subsection{Vitamin solubilization in mixed intestinal assemblies}

Accounting for the above results, two FA+MG concentrations were selected to test fat-soluble vitamin solubilization in unimodal distribution mixed intestinal assemblies of which the geometric dimensions could be accurately characterized. Those were the two extrema: 5 and $40 \mathrm{mg} \mathrm{mL}^{-1}$ (denoted FA+MG 5 and FA+MG 40).

\subsubsection{Dynamic light scattering}

Examples of size measurements as a function of $\alpha$-tocopherol (VE) concentration in OA+MO mixed intestinal assemblies are reported in figure 6 . It shows that Dn at the lowest VE concentration was slightly larger than without VE (see figure 1). Then, it increased or fluctuated with increasing VE concentration in $\mathrm{OA}+\mathrm{MO} 5$ or $\mathrm{OA}+\mathrm{MO} 40$ systems, respectively. Above a critical VE concentration, there was an abrupt transition of the diameter value, increasing above $100 \mathrm{~nm}$, the number-based size

371 distribution becoming bimodal (Dn was determined for the major peak). We defined this critical 372 concentration as the solubilization capacity, above which the vitamin is not solubilized in the initial 
assembly anymore. In figure 6 , its values were reproducibly of 7.9 and $12.6 \mathrm{mg} \mathrm{mL}^{-1}$ in OA+MO 5 and $\mathrm{OA}+\mathrm{MO} 40$ systems, respectively. The same experiments were done for the other FA+MG systems, all displaying an abrupt transition at a critical VE concentration. The other vitamins were also tested in all FA+MG systems at 5 and $40 \mathrm{mg} \mathrm{mL}^{-1}$, phylloquinone (VK) and retinol (VA) systems also displaying an abrupt size transition. However, for VA, such a transition was only found in micellar systems, no transition being detected in vesicular systems.
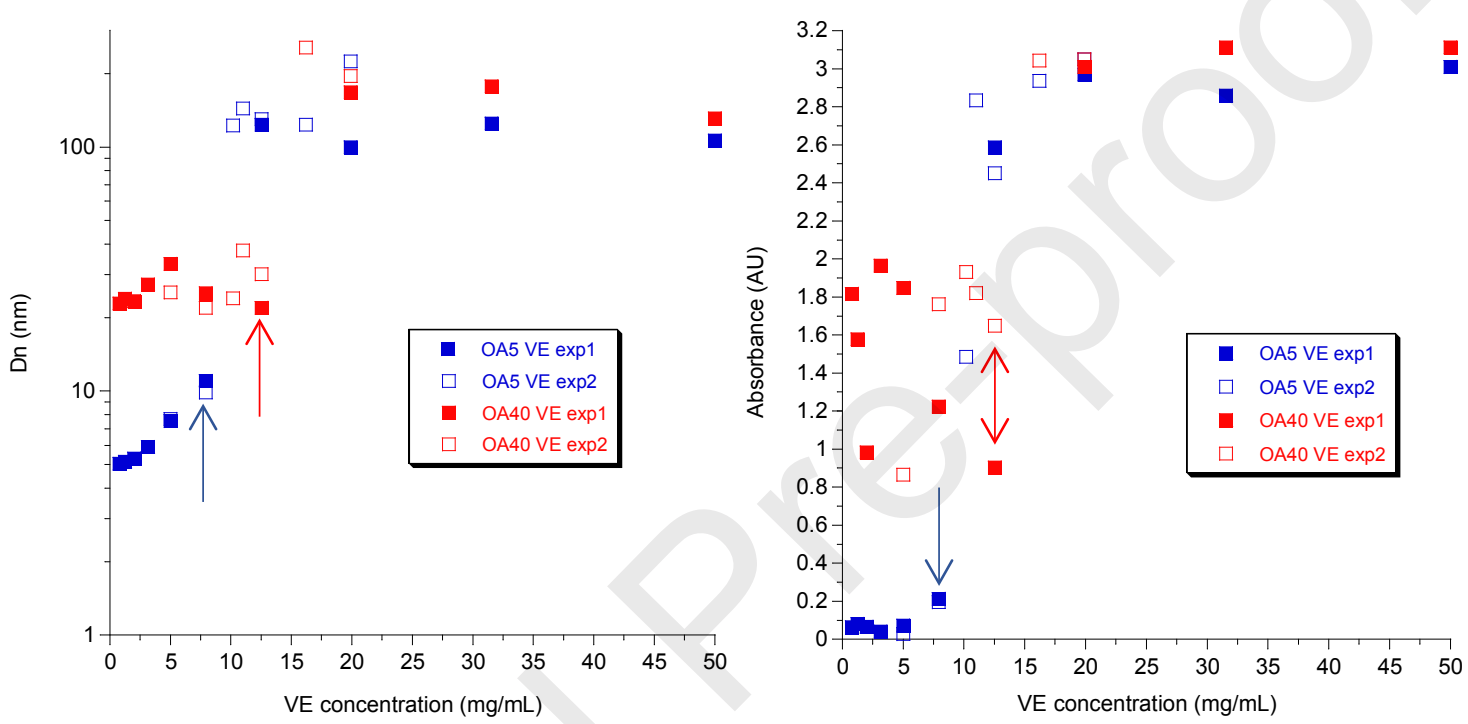

Figure 6: Dn and absorbance of mixed intestinal assemblies as a function of VE concentration in OA+MO 5 or OA+MO 40 systems. The arrows indicate the solubilization capacity.

The vitamin solubilization capacity ranges determined by DLS are shown in figure 7 . The solubilization capacity of the mixed intestinal assemblies depended more on the FA+MG concentration than on the FA+MG type. The solubilization capacity also depended on the vitamin type, higher amounts of VE being solubilized compared to VA and VK (lowest amounts for VK). In all systems, cholecalciferol (VD) addition did not induce any abrupt transition, diameter being constant up to very high concentrations. Only concentrations above $1 \mathrm{mg} \mathrm{mL}^{-1}$ resulted in a slight diameter increase. 

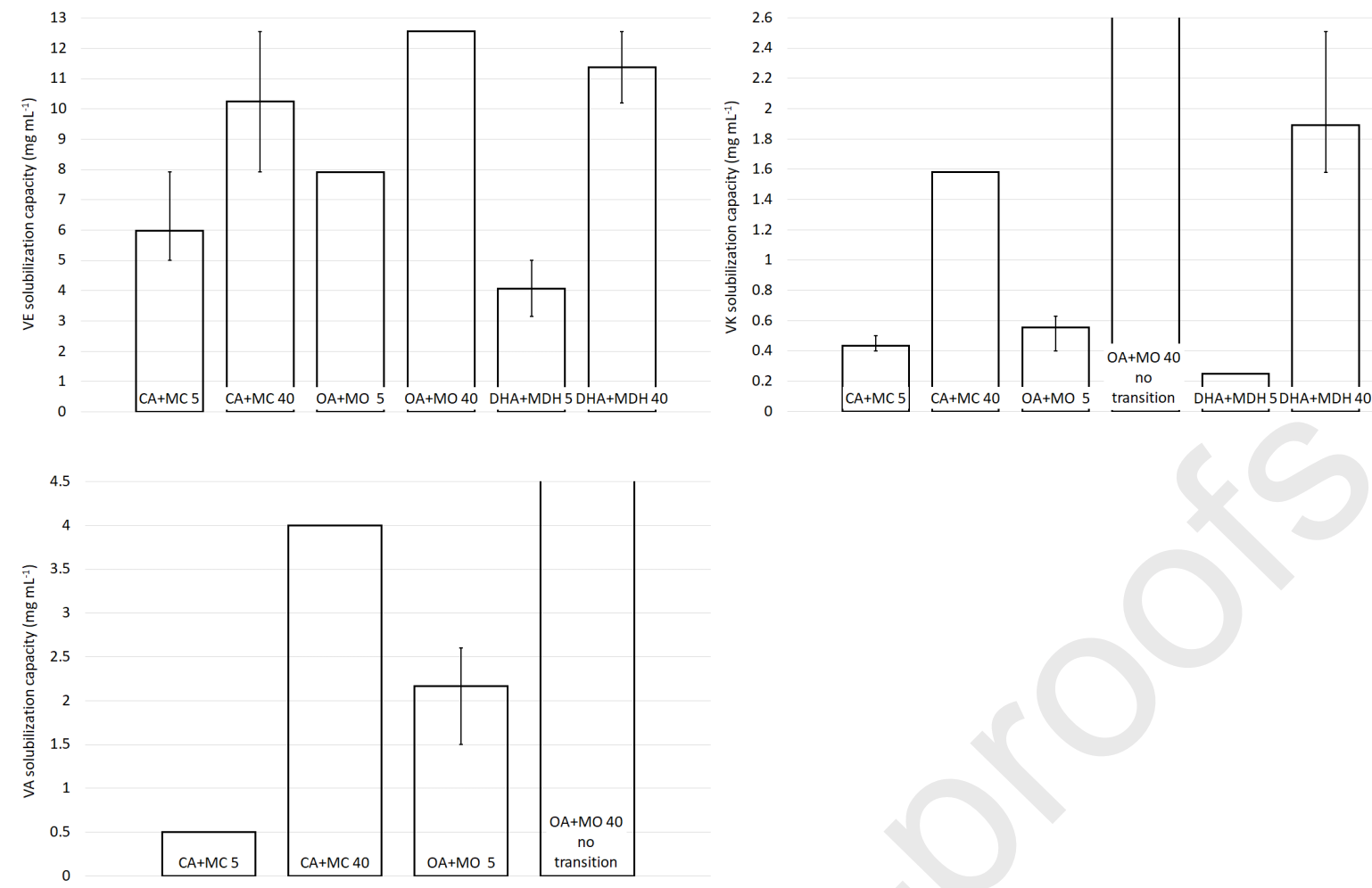

Figure 7: Solubilization capacity mean and range for VE (left), VK (right), or VA (bottom) as determined by DLS.

When no range appears, values were reproducible ( 2 to 3 independent samples series). Bars higher than the scale maximum means that no transition was found in the vitamin range investigated.

\subsubsection{Turbidimetry}

Mixed intestinal assemblies containing the different vitamins were also analyzed using turbidimetry.

The results for the same systems presented above are also shown in figure 6 . Similar trends were observed, with abrupt transitions at the same critical concentrations than those determined by DLS.

Again, this type of behavior was found for VE, VK, and VA, but not for VD, inducing no abrupt turbidity change within its concentration range (table 3 ). Overall, the solubilization capacity values determined by turbidimetry were most of the time in agreement with those determined by DLS.

\subsubsection{Small angle $X$-ray scattering}

Mixed intestinal assemblies containing VE or VK at the solubilization capacity were characterized by SAXS. The concentrations of VD and VA were chosen to correspond to the upper intake (dose) in the 
profiles (see figures S3), the parameters for the core-multi-shell sphere models being reported in table

409 S2, and the SAXS curves and fits being reported in figures S3. When comparing the geometric

410 dimensions of the mixed intestinal assemblies with or without vitamin, it appeared that only VE had a

411 significant effect on micelles, systematically enlarging them. In contrast, vesicles could be either enlarged or reduced by any vitamin addition except VD, mainly by a modulation of the water core size.

\subsubsection{Cryo-TEM}

414 Mixed intestinal assemblies of OA+MO 5 and OA+MO 40 containing VE were also observed by cryo-
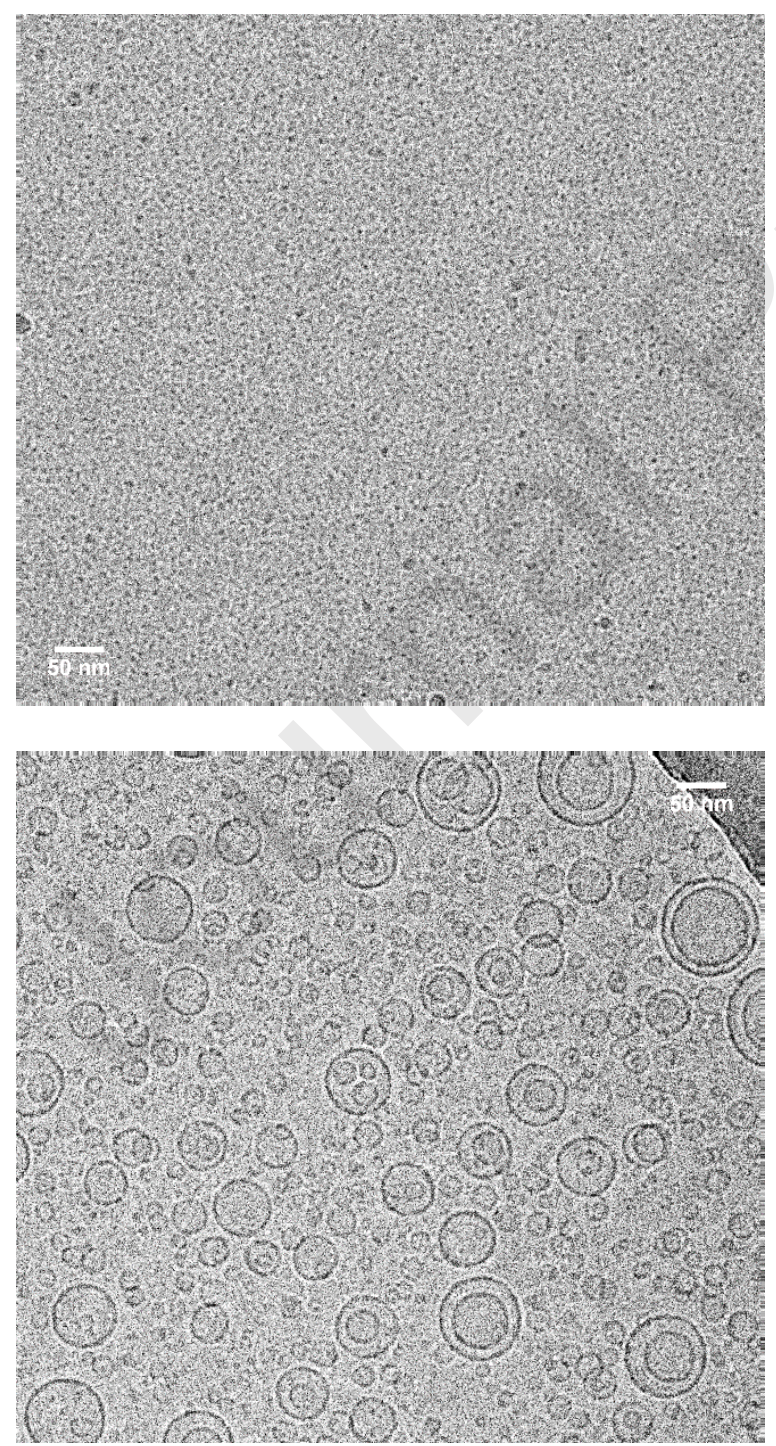
Figure 8: Representative cryo-TEM micrographs for OA+MO 5 VE 3 (VE at $3 \mathrm{mg} \mathrm{mL}^{-1}$, top), and OA+MO 40 VE 5

(VE at $5 \mathrm{mg} \mathrm{mL}^{-1}$, bottom) systems.

\section{Discussion}

\subsection{Mixed intestinal assemblies}

Size data on mixed intestinal assemblies including lysophospholipid (rather than phospholipid) are scarce, although lysophospholipid is the main phospholipid species in the small intestine (Arnesjo et al., 1969). Additionally, when considering different studies, size values can be difficult to compare as: i) systems are never entirely identical (different concentration, number, and type of components), and ii) DLS size distributions are not interpreted using the same mean value (number-based, volume-based, intensity-based, etc.). Nevertheless, for similar fed-state systems containing at least bile salt, lysophospholipid and OA, the DLS diameter (mean value types not known) of micelles was reported to be $5.7 \pm 0.6 \mathrm{~nm}$ (Fatouros et al., 2009b) or $5.3 \pm 0.5 \mathrm{~nm}$ (Birru et al., 2014), only slightly larger than the average value of Dn we obtained at low OA+MO concentrations, of $4.4 \pm 0.4 \mathrm{~nm}$ (figure 1). For other fed-state systems containing phospholipid, $\mathrm{OA}$, and $\mathrm{MO}$, micelles and vesicles of $33 \pm 4 \mathrm{~nm}$ and $55 \pm 3$ $\mathrm{nm}$ (intensity-based mean diameter, Nielsen et al., 2001), $8.2 \mathrm{~nm}$ and $140 \mathrm{~nm}$ (number-based mean diameter, Kossena et al., 2003), $5.2 \pm 0.2 \mathrm{~nm}, 27 \pm 2 \mathrm{~nm}$ and $90 \pm 18 \mathrm{~nm}$ (volume-based mean diameter, Ilardia-Arana et al., 2006), $5.8 \pm 0.5 \mathrm{~nm}$ and $67 \pm 14 \mathrm{~nm}$ (volume-based mean diameter, Kleberg et al., 2010) were reported. The micelle diameters are similar to our values, but the vesicle diameters are always significantly larger than the ones we reported here. In these articles, the $33 \mathrm{~nm}, 55 \mathrm{~nm}$, and 27 $\mathrm{nm}$ values were interpreted as mixed micelle diameters, but could more likely correspond to the small vesicles we identified here.

We used the same techniques as Birru et al. (2014) and obtained similar behaviors, validating the ability of DLS and turbidimetry to determine structural transitions. However, as their samples were not filtered, mixtures of micelles and very large vesicles (in the range $400-600 \mathrm{~nm}$ ) were obtained at high lysophospholipid+OA ratios (Birru et al., 2014). In our case, samples were filtered, removing assemblies 
above $220 \mathrm{~nm}$ (as seen in figure 6), in order to normalize preparation and characterize single assemblies (except in the transition regions). In a second study, mixtures of micelles and vesicles were obtained at high OA+MO ratios, with bimodal or trimodal distributions (unfiltered samples), the smallest mean size being about $30 \mathrm{~nm}$ (Birru et al., 2017). This size was interpreted as a large micelle diameter, but could again correspond to the small vesicles we identified here. In the first article reporting size transitions using DLS for mixed intestinal assemblies (with a phospholipid, and addition of $\mathrm{OA}, \mathrm{MO}$, and $\mathrm{DO}$ ), an abrupt transition from $6.0 \mathrm{~nm}$ micelles to $100 \mathrm{~nm}$ vesicles was also observed (Staggers et al., 1990).

Overall, the discrepancy in the size values might be due to: i) the use of different distribution types to calculate the mean diameter, ii) measurement difficulties in unfiltered samples containing coexisting assemblies (Kleberg et al., 2010; Birru et al., 2014; 2017), iii) the use of varying lipid/bile salt ratios at a constant total concentration, meaning that bile salt concentration decreases as lipid concentration increases (Staggers et al., 1990; Birru et al., 2014; 2017). In the present study, we used a constant bile salt concentration (constant SIB composition and concentration) and we increased FA+MG concentrations, resulting in transitions only depending on FA+MG concentration. The transition concentrations are thus difficult to compare to previous literature values. However, normalized mass solubilization ratio (SR) values are available for various fatty acids and monoglycerides in bile micelles (Marze, 2014). For CA, a SR of 3.5 was reported, which we did not exceed for CA alone, but that we exceeded for $C A+M C$, with no size or turbidity change. For $O A$ and $M O, S R$ values of 0.62 and 0.52 were reported, respectively. In our experiments, the pure micellar region exists up to a SR of 0.85 for $\mathrm{OA}+\mathrm{MO}$, in reasonable agreement.

When comparing the transitions determined by DLS and turbidimetry, the first technique identified well the end of the micelle region whereas the second technique identified well the start of the vesicle region. Thus, these techniques appeared to be complementary, but DLS provides important microscopic features (size distributions, mean sizes). Moreover, turbidity depends on both size and 
concentration, making it difficult to interpret highly turbid regions, such as the vesicle region where

472 turbidity increases continuously. The same was found by Birru et al. (2014; 2017).

473 SAXS experiments enabled a detailed characterization of the assembly structures. A transition from ellipsoidal micelles to spherical vesicles upon $\mathrm{OA}+\mathrm{MO}$ or $\mathrm{DHA}+\mathrm{MDH}$ addition was found in the current study. Although this does not agree with some previous studies reporting disk-like shape for fed-state intestinal micelles (Elvang et al., 2016; 2018; 2019; Hernell et al., 1990), this is consistent with other studies reporting spherical (Phan et al., 2015) or ellipsoidal shapes (Clulow et al., 2017; Rezhdo et al., 2017) for fed-state intestinal micelles. More precisely, the geometric diameters of our core-shell oblate ellipsoid micelles $(7.0 \pm 0.5 \mathrm{~nm} ; 3.6 \pm 0.8 \mathrm{~nm})$ are in good agreement with the core-shell oblate ellipsoid micelles of Clulow et al. $(6.6 \pm 0.1 \mathrm{~nm} ; 4.1 \pm 0.1 \mathrm{~nm})$ and the oblate ellipsoid micelles of Rezhdo et al. (6.4 $\pm 0.6 \mathrm{~nm} ; 3.7 \pm 0.1 \mathrm{~nm})$. Upon OA+MO addition, Clulow et al. (2017) reported an increase in the micelle size, and the appearance of another assembly around $26 \mathrm{~nm}$ (volume-based mean diameter). This size was interpreted as that for aggregated micelles, but could again correspond to the small vesicles we identified. Vesicles of similar size were indeed found in their fasted state system (modelled as core-multi-shell spheres). Moreover, such small vesicles (intensity-based mean diameter of 25-50 $\mathrm{nm}$ ) were also reported for bile salt+phospholipid systems at low salt concentration and high dilution (Leng et al., 2003). Concerning the vesicle membrane thickness, the values deduced from SAXS measurements $(5.1 \pm 0.1 \mathrm{~nm}$, table S2) are in very good agreement with the value of $5.2 \mathrm{~nm}$ deduced from SAXS measurements of a fed-state OA+MO system (Salentinig et al., 2011).

Our cryo-TEM observations confirmed that the systems at the highest OA+MO or DHA+MDH concentration are made of small vesicles. For similar systems containing $\mathrm{OA}+\mathrm{MO}$ and phospholipid, Fatouros et al. (2009a), using cryo-TEM, also observed small vesicles (below 40-50 nm) and large double or multiple vesicles (above $100 \mathrm{~nm}$ ). When the phospholipid was replaced by a 494 lysophospholipid, similar assemblies were observed (Fatouros et al., 2009b). After triolein in vitro digestion, Salentinig et al. (2011) also reported that digestion products (OA+MO) associated with bile salts and lysophospholipid to form small unilamellar vesicles (below $50 \mathrm{~nm}$, as observed by cryo-TEM). 
Finally, Riethorst et al. (2016) used different microscopy techniques to investigate human duodenal

fluid collected in the fed state, observing a mixture of micelles, vesicles, and droplets, vesicles being predominant. Vesicle size distribution was large, ranging from 10 to $500 \mathrm{~nm}$, again with small unilamellar vesicles and large multiple vesicles.

501

\subsection{Vitamin solubilization in mixed intestinal assemblies}

503

504

505

506

507

508

509

510

511

512

513

514

515

516

517

Concerning the techniques to determine solubilization capacity, both DLS and turbidimetry were used before to monitor the solubilization in synthetic surfactant solutions of lipophilic compounds (essential oil components, vitamins) at increasing concentrations. Similar DLS curves with a steep transition were obtained, assemblies being about $100 \mathrm{~nm}$ or even more above the transition (Rao and McClements, 2012; Ziani et al., 2012). Turbidimetry alone was used in the context of VE solubilization in mixed bile micelles, a transition being also evidenced (Yang and McClements, 2013). Although most of our turbidimetry results were in agreement with our DLS results, this was not always the case. Moreover, transitions can be difficult to identify when a continuous turbidity increase is observed (Rao and McClements, 2012; Ziani et al., 2012). Thus, we consider DLS more relevant for vitamin solubilization studies as it enables the precise determination of successive characteristic sizes in the system depending on vitamin concentration, making it possible to define a solubilization capacity in a specific assembly.

To understand the differences in solubilization capacity for the vitamins, we compared the mass solubilization ratios (SR) determined by DLS to those reported in the literature. For VE, our average SR range was from 0.41 to 1.26 , which is higher than the literature ranges of $0.14-0.33$ (Nielsen et al., 2001) and 0.1-0.2 (Yang and McClements, 2013) in similar conditions but at lower FA and/or MG concentrations, and 0.1-0.2 in low-concentration taurocholate or taurocholate-phosphatidylcholine (Imai et al., 1983). This discrepancy is likely due to much higher FA+MG concentrations in our systems. It was indeed shown that high FA+MG concentrations greatly enhanced drug solubilization (Kossena et al., 2003; 2004; Kleberg et al., 2010). 
For VK, our average SR range was from 0.025 to 0.19 , which is close to the range reported before, from 0.02 to 0.25 in high-concentration cholate or cholate-phosphatidylcholine (Nagata et al., 1988). For VA, our average SR range was from 0.05 to 0.4 , which is higher than the literature values of 0.002 for retinol in similar conditions but at lower FA+MG concentration (El-Gorab and Underwood, 1973) and 0.02 for retinyl palmitate in similar mixtures but in fasted state conditions (Desmarchelier et al., 2018). This could be due to our higher FA+MG concentrations again. Assembly filtration could also explain the difference, as it was shown to retain a large proportion of retinyl palmitate, resulting in an apparent lower solubilization capacity (Desmarchelier et al., 2018). We checked this in our conditions, and no significant effect of the filtrations was found on VA concentration in the assemblies within the concentration range studied, possibly because we used retinol rather than retinyl palmitate. Another critical aspect is vitamin degradation during assembly preparation, which is rarely reported in the literature. For an unmeasured high vitamin degradation, the solubilization capacity will indeed appear higher. As retinol was the most unstable vitamin we investigated, validation experiments were conducted in assemblies containing this molecule compared to the same assemblies containing $\alpha$ tocopherol. This showed that VA can be degraded up to $50 \%$ after 12 hours (VE was not significantly degraded in the assemblies after 24 hours). Once samples containing VA were prepared on ice, degradation was kept within $10-20 \%$ after 12 hours. When investigating the solubilization capacity, it is thus important to work within $12-24$ hours to limit degradation, and even better to quantify degradation.

For VD, no steep assembly transition was observed, although SR values up to 0.3 were investigated, at least 2-fold higher than those previously studied (Goncalves et al., 2011; Desmarchelier et al., 2018). It was recently shown that cholecalciferol could self-assemble alone in water, thus able to solubilize in the absence of other amphiphilic molecule (Desmarchelier et al., 2018). This might explain why we did not observe any significant assembly change up to high VD concentrations (human nutrition range), VD not being incorporated in mixed intestinal assemblies but forming self-assemblies on its own. We checked this possibility by DLS for $0.14 \mathrm{mg} \mathrm{mL}^{-1}$ VD alone in PBS, and found a Dn of $93 \pm 11 \mathrm{~nm}$, in 
agreement with the size range observed by Desmarchelier et al. (2018) using cryo-TEM. However, this

550 size was not detected in any mixed intestinal assembly system containing $0.14 \mathrm{mg} \mathrm{mL}^{-1} \mathrm{VD}$, and the

SAXS intensity profiles did not change either with $0.14 \mathrm{mg} \mathrm{mL}^{-1} \mathrm{VD}$ addition. This might be due to the small amount of VD relative to the other components in the systems, too small to be detected as selfassemblies and not inducing any structural change of the mixed intestinal assemblies.

As already discussed, any size change or abrupt transition upon vitamin incorporation should be reported, as these changes modify the interpretation of vitamin solubilization. Up to now, only one article dealing with similar systems reported sizes at the solubilization capacity, proving that the assembly size did not change upon $\alpha$-tocopherol incorporation (Nielsen et al., 2001). This is even more critical since most research groups used the excess vitamin method (addition of vitamin in large excess of the assembly solubilization capacity, then removal of the excess), very likely to induce a change in the size and structure of the solubilizing assembly. In this regard, the techniques we used here (turbidimetry and especially DLS) were more suitable, as vitamin was added gradually in the solubilizing assembly (from below the solubilization capacity).

Finally, the supramolecular structure characterization from SAXS enabled reasonable assumptions on vitamin localization in the assemblies. From the geometric dimensions and conformation of the most abundant and most constraining species, plus the comparison of the SLD values of individual species and those of the regions deduced from SAXS sphere models, ideal molecular organizations can be proposed. These are summed up in figure 9. Note that these organizations are only relevant for the localization of the molecules in the different regions (lipid tails region and headgroups/surface molecules region), not for their relative arrangement and amounts. The molecules taken into account were the bile salt dimer (Mazer et al., 1980; Mazer and Carey, 1983), the saturated carbon chain lysophospholipid (longest straight chain and large headgroup), CA and MC (straight chain), OA and MO (bent chain due to the double bond, cf. Rich, 1993), DHA and MDH (folded structure due to the six double bonds, cf. Albrand et al., 1994), and $\alpha$-tocopherol (straight chain, cf. Setiadi et al., 2003). As 
574 seen in figure 9, these molecules match most of the characteristic lengths of the assemblies, validating

575 the assembly core-shell structures and sizes at the molecular scale. 


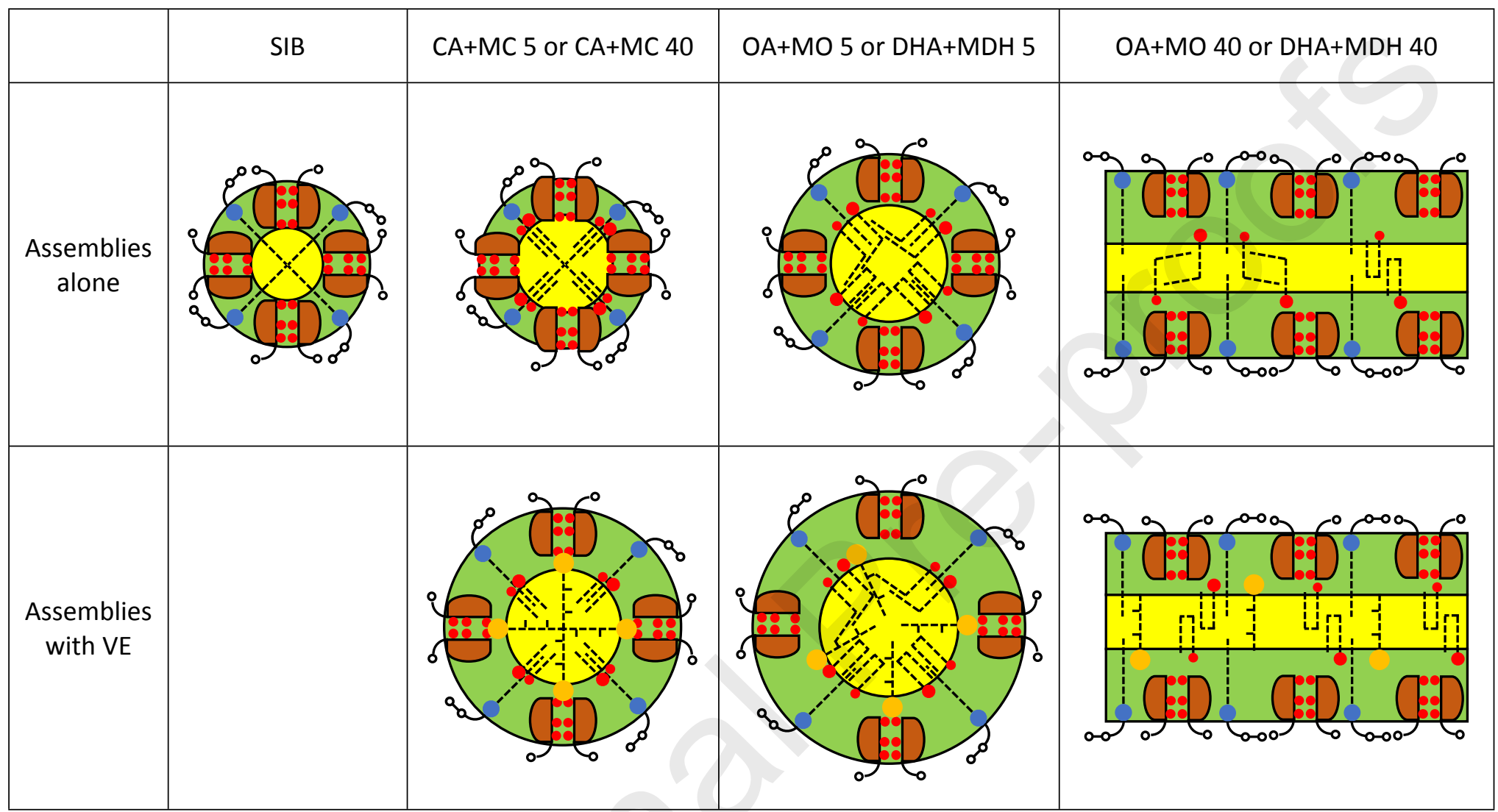

Figure 9: Molecular organization of assemblies inferred from SAXS measurements and models, plus molecular geometric dimensions and conformations. Headgroups/surface molecules region is green, lipid tails region is yellow, TC dimer is brown and red, 16:0 LPC polar head is blue, FA and MG polar heads are red, and VE ( $\alpha$-tocopherol) polar head is orange. All dimensions are to scale. Only a portion of the vesicle membrane is drawn for OA+MO 40 or DHA+MDH 40 . When OA+MO and DHA+MDH are drawn in the same assembly, assembly dimensions are not significantly different (only OA+MO $40 \mathrm{VE}$ and DHA+MDH 40 VE are significantly different). 


\section{Conclusion}

In this study, DLS was found to be the most appropriate method to monitor size transitions of bile intestinal assemblies upon addition of FA+MG and fat-soluble vitamins. The solubilization capacities in assemblies of specific structure could indeed be determined from DLS measurements. SAXS and cryoTEM experiments complemented these results by revealing the supramolecular structure of these assemblies, i.e. core-shell micelles at low FA+MG concentrations and unilamellar vesicles at high FA+MG concentrations (except with caprylate FA+MG, always yielding micelles). Moreover, SAXS data allowed ideal molecular organizations to be proposed.

For the first time, we showed that the incorporation of a fat-soluble vitamin in these micelles and vesicles either induced a systematic structural transition ( $\alpha$-tocopherol VE, phylloquinone VK), or induced a structural transition only for micelles (retinol VA), or no transition at all (cholecalciferol VD). So, confirming our hypothesis, the type and concentration of FA+MG clearly influenced both the structure of the assembly and its solubilization capacity for most of the fat-soluble vitamins studied. Our systematic investigation provides important new solubilization and structure data in many conditions, and proves that structural changes induced by a solubilizate should always be considered to correctly determine the solubilization capacity in a specific assembly. The precise structures above the solubilization capacity should also be characterized in future studies. Thus, our approach and results fill gaps in both methodology and knowledge of mixed intestinal assemblies structure and vitamin solubilization in the fed state, interesting for many applications (colloid science, nutrition, pharmacology, toxicology). More experimental works together with dynamic molecular simulations are currently performed to understand the molecular determinants of these results. In vivo experiments in the mouse are also conducted to determine the role of the intestinal assembly structure on fat-soluble vitamin absorption in the context of nutrition.

\section{Acknowledgments}

This work was supported by Agence Nationale de la Recherche (grant ANR-18-CE21-0002). 
References

611

612

613

614

615

616

617

618

619

620

621

622

623

624

625

626

627

628

629

630

631

632

633

634

635

636

637

638

639

640

641

642

Agellon LB, Walkey CJ, Vance DE, Kuipers F, Verkade HJ. 1999. The unique acyl chain specificity of biliary phosphatidylcholines in mice is independent of their biosynthetic origin in the liver. Hepatology 30:725-9

Albrand M, Pageaux JF, Lagarde M, Dolmazon R. 1994. CONFORMATIONAL-ANALYSIS OF ISOLATED DOCOSAHEXAENOIC ACID (22/6 N-3) AND ITS 14-(S) AND 11-(S) HYDROXY DERIVATIVES BY FORCE-FIELD CALCULATIONS. Chemistry and Physics of Lipids 72:7-17

Arnesjo B, Nilsson A, Barrowman J, Borgstrom B. 1969. INTESTINAL DIGESTION AND ABSORPTION OF CHOLESTEROL AND LECITHIN IN HUMAN - INTUBATION STUDIES WITH A FAT-SOLUBLE REFERENCE SUBSTANCE. Scandinavian Journal of Gastroenterology 4:653-+

Baghdasaryan A, Fuchs CD, Osterreicher CH, Lemberger UJ, Halilbasic E, et al. 2016. Inhibition of intestinal bile acid absorption improves cholestatic liver and bile duct injury in a mouse model of sclerosing cholangitis. Journal of Hepatology 64:674-81

Bizien T, Ameline JC, Yager KG, Marchi V, Artzner F. 2015. Self-Organization of Quantum Rods Induced by Lipid Membrane Corrugations. Langmuir 31:12148-54

Birru WA, Warren DB, Han SF, Benameur H, Porter CJH, et al. 2017. Computational Models of the Gastrointestinal Environment. 2. Phase Behavior and Drug Solubilization Capacity of a Type I Lipid-Based Drug Formulation after Digestion. Molecular Pharmaceutics 14:580-92

Birru WA, Warren DB, Ibrahim A, Williams HD, Benameur H, et al. 2014. Digestion of Phospholipids after Secretion of Bile into the Duodenum Changes the Phase Behavior of Bile Components. Molecular Pharmaceutics 11:2825-34

Boquillon M, Clement J. 1979. EFFECT OF TYPE AND AMOUNT OF DIETARY-FAT ON BILE-FLOW AND COMPOSITION IN RATS. Annales De Biologie Animale Biochimie Biophysique 19:1725-36

Carey MC, Small DM. 1970. CHARACTERISTICS OF MIXED MICELLAR SOLUTIONS WITH PARTICULAR REFERENCE TO BILE. American Journal of Medicine 49:590-\&

Clulow AJ, Parrow A, Hawley A, Khan J, Pham AC, et al. 2017. Characterization of Solubilizing Nanoaggregates Present in Different Versions of Simulated Intestinal Fluid. Journal of Physical Chemistry B 121:10869-81

Cohen DE, Thurston GM, Chamberlin RA, Benedek GB, Carey MC. 1998. Laser light scattering evidence for a common wormlike growth structure of mixed micelles in bile salt- and straight-chain detergent-phosphatidylcholine aqueous systems: Relevance to the micellar structure of bile. Biochemistry 37:14798-814

Desmarchelier C, Rosilio V, Chapron D, Makky A, Preveraud DP, et al. 2018. Molecular interactions 
governing the incorporation of cholecalciferol and retinyl-palmitate in mixed taurocholatelipid micelles. Food Chemistry 250:221-9

Dubochet J, McDowall AW. 1981. VITRIFICATION OF PURE WATER FOR ELECTRON-MICROSCOPY. Journal of Microscopy-Oxford 124:RP3-RP4

Egelhaaf SU, Schurtenberger P. 1999. Micelle-to-vesicle transition: A time-resolved structural study. Physical Review Letters 82:2804-7

El-Gorab M, Underwood BA. 1973. SOLUBILIZATION OF BETA-CAROTENE AND RETINOL INTO AQUEOUS-SOLUTIONS OF MIXED MICELLES. Biochimica Et Biophysica Acta 306:58-66

Elvang PA, Bohsen MS, Stein PC, Bauer-Brandl A, Riethorst D, et al. 2019. Co-existing colloidal phases of human duodenal aspirates: Intraindividual fluctuations and interindividual variability in relation to molecular composition. Journal of Pharmaceutical and Biomedical Analysis 170:229

Elvang PA, Hinna AH, Brouwers J, Hens B, Augustijns P, Brandl M. 2016. Bile Salt Micelles and Phospholipid Vesicles Present in Simulated and Human Intestinal Fluids: Structural Analysis by Flow FieldeFlow Fractionation/Multiangle Laser Light Scattering. Journal of Pharmaceutical Sciences 105:2832-9

Elvang PA, Jacobsen AC, Bauer-Brandl A, Stein PC, Brandl M. 2018. Co-existing colloidal phases in artificial intestinal fluids assessed by AF4/MALLS and DLS: A systematic study into cholate \& (lyso-) phospholipid blends, incorporating celecoxib as a model drug. European Journal of Pharmaceutical Sciences 120:61-72

Fatouros DG, Walrand I, Bergenstahl B, Mullertz A. 2009. Colloidal Structures in Media Simulating Intestinal Fed State Conditions with and Without Lipolysis Products. Pharmaceutical Research 26:361-74

Fatouros DG, Walrand I, Bergenstahl B, Mullertz A. 2009. Physicochemical Characterization of Simulated Intestinal Fed-State Fluids Containing Lyso-Phosphatidylcholine and Cholesterol. Dissolution Technologies 16:47-50

Goncalves A, Gleize B, Bott R, Nowicki M, Amiot MJ, et al. 2011. Phytosterols can impair vitamin D intestinal absorption in vitro and in mice. Molecular Nutrition \& Food Research 55:S303-S11

Grundy SM, Metzger AL. 1972. PHYSIOLOGICAL METHOD FOR ESTIMATION OF HEPATIC SECRETION OF BILIARY LIPIDS IN MAN. Gastroenterology 62:1200-\&

Hernell O, Staggers JE, Carey MC. 1990. PHYSICAL-CHEMICAL BEHAVIOR OF DIETARY AND BILIARY LIPIDS DURING INTESTINAL DIGESTION AND ABSORPTION .2. PHASE-ANALYSIS AND AGGREGATION STATES OF LUMINAL LIPIDS DURING DUODENAL FAT DIGESTION IN HEALTHY ADULT HUMAN-BEINGS. Biochemistry 29:2041-56

Hjelm RP, Thiyagarajan P, Alkanonyuksel H. 1992. ORGANIZATION OF PHOSPHATIDYLCHOLINE AND 
BILE-SALT IN RODLIKE MIXED MICELLES. Journal of Physical Chemistry 96:8653-61

Ilardia-Arana D, Kristensen HG, Mullertz A. 2006. Biorelevant dissolution media: Aggregation of amphiphiles and solubility of estradiol. Journal of Pharmaceutical Sciences 95:248-55

Imai J, Hayashi M, Awazu S, Hanano M. 1983. SOLUBILIZATION OF DL-ALPHA-TOCOPHEROL BY BILESALTS, POLYSORBATE-80 AND EGG LECITHIN. Chemical \& Pharmaceutical Bulletin 31:4077-82 Juste C, Demarne Y, Corring T. 1983. RESPONSE OF BILE-FLOW, BILIARY LIPIDS AND BILE-ACID POOL IN THE PIG TO QUANTITATIVE VARIATIONS IN DIETARY-FAT. Journal of Nutrition 113:1691-701

Kleberg K, Jacobsen F, Fatouros DG, Mullertz A. 2010. Biorelevant Media Simulating Fed State Intestinal Fluids: Colloid Phase Characterization and Impact on Solubilization Capacity. Journal of Pharmaceutical Sciences 99:3522-32

Kok T, Hulzebos CV, Wolters H, Havinga R, Agellon LB, et al. 2003. Enterohepatic circulation of bile salts in farnesoid $\mathrm{x}$ receptor-deficient mice - Efficient intestinal bile salt absorption in the absence of ileal bile acid-binding protein. Journal of Biological Chemistry 278:41930-7

Kossena GA, Boyd BJ, Porter CJH, Charman WN. 2003. Separation and characterization of the colloidal phases produced on digestion of common formulation lipids and assessment of their impact on the apparent solubility of selected poorly water-soluble drugs. Journal of Pharmaceutical Sciences 92:634-48

Kossena GA, Charman WN, Boyd BJ, Dunstan DE, Porter CJH. 2004. Probing drug solubilization patterns in the gastrointestinal tract after administration of lipid-based delivery systems: A phase diagram approach. Journal of Pharmaceutical Sciences 93:332-48

Leng J, Egelhaaf SU, Cates ME. 2003. Kinetics of the micelle-to-vesicle transition: Aqueous lecithin-bile salt mixtures. Biophysical Journal 85:1624-46

Madenci D, Salonen A, Schurtenberger P, Pedersen JS, Egelhaaf SU. 2011. Simple model for the growth behaviour of mixed lecithin-bile salt micelles. Physical Chemistry Chemical Physics 13:3171-8

Marze S. 2014. A coarse-grained simulation to study the digestion and bioaccessibility of lipophilic nutrients and micronutrients in emulsion. Food \& Function 5:129-39

Mazer NA, Benedek GB, Carey MC. 1980. QUASI-ELASTIC LIGHT-SCATTERING-STUDIES OF AQUEOUS BILIARY LIPID SYSTEMS - MIXED MICELLE FORMATION IN BILE-SALT LECITHIN SOLUTIONS. Biochemistry 19:601-15

Mazer NA, Carey MC. 1983. QUASI-ELASTIC LIGHT-SCATTERING-STUDIES OF AQUEOUS BILIARY LIPID SYSTEMS - CHOLESTEROL SOLUBILIZATION AND PRECIPITATION IN MODEL BILE SOLUTIONS. Biochemistry 22:426-42

Muller K. 1981. STRUCTURAL DIMORPHISM OF BILE-SALT LECITHIN MIXED MICELLES - A POSSIBLE REGULATORY MECHANISM FOR CHOLESTEROL SOLUBILITY IN BILE - X-RAY STRUCTUREANALYSIS. Biochemistry 20:404-14 
Nagata M, Yotsuyanagi T, Ikeda K. 1988. SOLUBILIZATION OF VITAMIN-K1 BY BILE-SALTS AND PHOSPHATIDYLCHOLINE-BILE SALTS MIXED MICELLES. Journal of Pharmacy and Pharmacology 40:85-8

Nichols JW, Ozarowski J. 1990. SIZING OF LECITHIN-BILE SALT MIXED MICELLES BY SIZE-EXCLUSION HIGH-PERFORMANCE LIQUID-CHROMATOGRAPHY. Biochemistry 29:4600-6

Nielsen PB, Mullertz A, Norling T, Kristensen HG. 2001. The effect of alpha-tocopherol on the in vitro solubilisation of lipophilic drugs. International Journal of Pharmaceutics 222:217-24

Pathak P, Xie C, Nichols RG, Ferrell JM, Boehme S, et al. 2018. Intestine farnesoid X receptor agonist and the gut microbiota activate G-protein bile acid receptor-1 signaling to improve metabolism. Hepatology 68:1574-88

Phan S, Salentinig S, Gilbert E, Darwish TA, Hawley A, et al. 2015. Disposition and crystallization of saturated fatty acid in mixed micelles of relevance to lipid digestion. Journal of Colloid and Interface Science 449:160-6

Rao JJ, McClements DJ. 2012. Lemon oil solubilization in mixed surfactant solutions: Rationalizing microemulsion \& nanoemulsion formation. Food Hydrocolloids 26:268-76

Reeves PG, Nielsen FH, Fahey GC. 1993. AIN-93 PURIFIED DIETS FOR LABORATORY RODENTS - FINAL REPORT OF THE AMERICAN INSTITUTE OF NUTRITION AD HOC WRITING COMMITTEE ON THE REFORMULATION OF THE AIN-76A RODENT DIET. Journal of Nutrition 123:1939-51

Rezhdo O, Di Maio S, Le P, Littrell KC, Carrier RL, Chen SH. 2017. Characterization of colloidal structures during intestinal lipolysis using small-angle neutron scattering. Journal of Colloid and Interface Science 499:189-201

Rich MR. 1993. CONFORMATIONAL-ANALYSIS OF ARACHIDONIC AND RELATED FATTY-ACIDS USING MOLECULAR-DYNAMICS SIMULATIONS. Biochimica Et Biophysica Acta 1178:87-96

Riethorst D, Baatsen P, Remijn C, Mitra A, Tack J, et al. 2016. An In-Depth View into Human Intestinal Fluid Colloids: Intersubject Variability in Relation to Composition. Molecular Pharmaceutics $13: 3484-93$

Salentinig S, Sagalowicz L, Leser ME, Tedeschi C, Glatter O. 2011. Transitions in the internal structure of lipid droplets during fat digestion. Soft Matter 7:650-61

SasView website: https://www.sasview.org

Schurtenberger P, Mazer N, Kanzig W. 1985. MICELLE TO VESICLE TRANSITION IN AQUEOUSSOLUTIONS OF BILE-SALT AND LECITHIN. Journal of Physical Chemistry 89:1042-9

Setiadi DH, Chass GA, Koo JCP, Penke B, Csizmadia IG. 2003. Exploratory study on the full conformation space of alpha-tocopherol and its selected congeners. Journal of Molecular StructureTheochem 666:439-43

Small DM, Penkett SA, Chapman D. 1969. STUDIES ON SIMPLE AND MIXED BILE SALT MICELLES BY 
NUCLEAR MAGNETIC RESONANCE SPECTROSCOPY. Biochimica Et Biophysica Acta 176:178-\&

749

750

751

752

753

754

755

756

757

758

759

760

761

762

763

764

765

766

767

768

769

770

771

Staggers JE, Hernell O, Stafford RJ, Carey MC. 1990. PHYSICAL-CHEMICAL BEHAVIOR OF DIETARY AND BILIARY LIPIDS DURING INTESTINAL DIGESTION AND ABSORPTION .1. PHASE-BEHAVIOR AND AGGREGATION STATES OF MODEL LIPID SYSTEMS PATTERNED AFTER AQUEOUS DUODENAL CONTENTS OF HEALTHY ADULT HUMAN-BEINGS. Biochemistry 29:2028-40

Sugano $\mathrm{M}$, Watanabe $\mathrm{M}$, Kohno $\mathrm{M}$, Cho YJ, Ide T. 1983. EFFECTS OF DIETARY TRANS-FAT ON BILIARY AND FECAL STEROID-EXCRETION AND SERUM-LIPOPROTEINS IN RATS. Lipids 18:375-81

Tannock GW, Tangerman A, Vanschaik A, McConnell MA. 1994. DECONJUGATION OF BILE-ACIDS BY LACTOBACILLI IN THE MOUSE SMALL-BOWEL. Applied and Environmental Microbiology $60: 3419-20$

Ulmius J, Lindblom G, Wennerstrom H, Johansson LBA, Fontell K, et al. 1982. MOLECULARORGANIZATION IN THE LIQUID-CRYSTALLINE PHASES OF LECITHIN SODIUM CHOLATE WATERSYSTEMS STUDIED BY NUCLEAR MAGNETIC-RESONANCE. Biochemistry 21:1553-60

Werner A, Minich DM, Havinga R, Bloks V, Van Goor H, et al. 2002. Fat malabsorption in essential fatty acid-deficient mice is not due to impaired bile formation. American Journal of PhysiologyGastrointestinal and Liver Physiology 283:G900-G8

Wiedmann TS, Kamel L. 2002. Examination of the solubilization of drugs by bile salt micelles. Journal of Pharmaceutical Sciences 91:1743-64

Yang Y, McClements DJ. 2013. Vitamin E and Vitamin E acetate solubilization in mixed micelles: Physicochemical basis of bioaccessibility. Journal of Colloid and Interface Science 405:312-21

Ziani K, Fang Y, McClements DJ. 2012. Encapsulation of functional lipophilic components in surfactantbased colloidal delivery systems: Vitamin E, vitamin D, and lemon oil. Food Chemistry 134:1106-12 
772

773 Graphical abstract

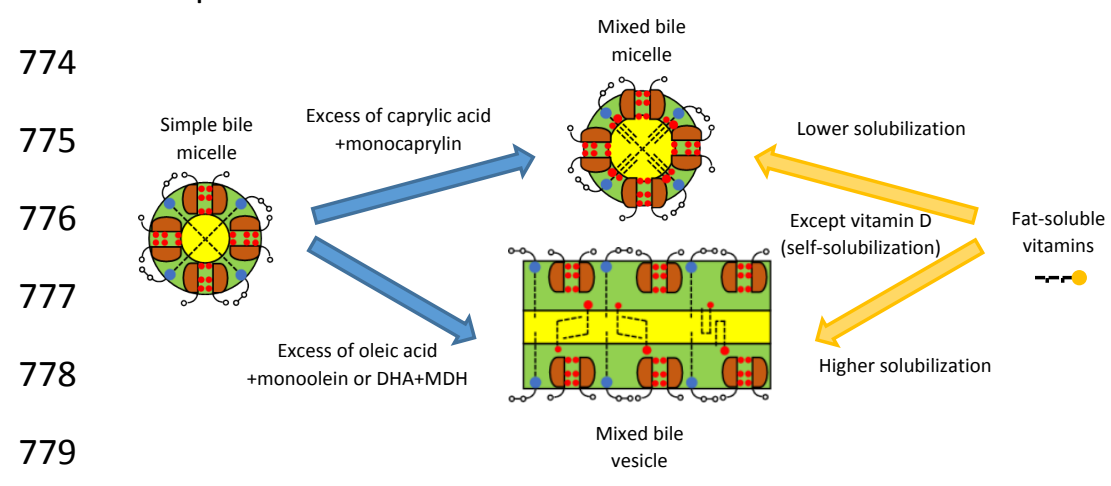

780

781

782

783

784

785 
786 Asma El Aoud: Methodology, Investigation, Visualization, Formal analysis, Writing - Original Draft

787 Emmanuelle Reboul: Methodology, Supervision, Writing - Review \& Editing

788 Aurélien Dupont: Investigation, Visualization

789 Cristelle Mériadec: Investigation, Visualization

790 Franck Artzner: Methodology, Investigation, Visualization, Writing - Review \& Editing

791 Sébastien Marze: Conceptualization, Supervision, Project administration, Funding acquisition,

792 Methodology, Investigation, Visualization, Formal analysis, Writing - Original Draft, Writing - Review

793 \& Editing 